УДК 618.252

DOI: 10.18101/2306-1995-2019-1-58-61

\title{
МНОГОПЛОДНАЯ БЕРЕМЕННОСТЬ
}

\author{
(C) Гармаева Евгения Данзановна \\ кандидат медицинских наук, \\ зав. ОПБ ГАУЗ «Городской перинатальный центр»
}

\author{
(C) Ботоева Елена Аполлоновна \\ кандидат медицинских наук, доцент, \\ Бурятский государственный университет им. Д. Банзарова \\ Россия, Улан-Удэ, 670002, ул. Октябрьская, 36а \\ E-mail: elenabotoeva@list.ru
}

В настоящее время была выявлена тенденция увеличения частоты многоплодных беременностей. Это обусловлено обширным применением оральной контрацепции, после отмены которого отмечается спонтанное созревание двух и более фолликулов, а так же введением в практику дополнительных репродуктивных технологий, сопряженных с индукцией суперовуляции. Монохориальная беременность, среди всего числа многоплодных беременностей, является наиболее прогностически неблагоприятной. Перинатальные осложнения и смертность при такой беременности составляет $10 \%$, что превышает уровень осложнений при дихориальной двойне в 3-4 раза. Причины данной ситуации лежат в особенностях строения общей плаценты: зачастую существование плацентарных сосудистых анастомозов могут приводить к гемодинамическому дисбалансу между близнецами. Синдром обратной артериальной перфузии у двойни является одним из наиболее ярких проявлений аномального анастомозирования сосудов в монохориальной плаценте и проявляется пороками развития плода (так называемые пороки - «акардиальный монстр», «аненцефальная акардия»).

В статье рассматривается проблема осложнений, сопряженных с многоплодной беременностью, а так же приводится описание случая пренатальной диагностики синдрома обратной артериальной перфузии при монохориальной моноамниотической двойне.

Ключевые слова: многоплодная беременность, репродукция, суперовуляция, созревание

Для цитирования:

Гармаева Е. Д., Ботоева Е. А. Многоплодная беременность // Вестник Бурятского государственного университета. Медицина и фармация. 2019. Вып. 1. С. 58-61.

Частота выявления синдрома в популяции - 1:35 000. Один из плодов в паpe с обратной артериальной перфузией является близнецом-донором, второй близнецом-реципиентом. Близнец-донор будет иметь нормальный кариотип и анатомию, однако у него вероятно выявление признаков перегрузки сердца в виде гипертрофии правого желудочка, гидроперикарда, а так же гепатоспленомегалии и неимммунной водянки; могут быть признаки синдрома задержки внутриутробного развития. Сердечная недостаточность и морфологическая незрелость обуславливает высокий уровень смертности и перинатальных осложнений (55\%).

В свою очередь, у близнеца-реципиента так же отмечаются множественные пороки развития: пороки лица, полное или частичное отсутствие сводов черепа, голопрозэнцефалия, гастрошизис, дефекты диафрагмы, отсутствие легких и 
сердца, отсутствие или недоразвитие конечностей. В большинстве случаев у близнеца-реципиента выявлен аномальный кариотип (50\%).

Описание клинического случая. Пациентка Ю. 28 лет была направлена в акушерское отделение патологии беременности на дородовую госпитализацию с диагнозом: Беременность 37-38 недель. ОАА. ЭКО+ИКСИ. Монохориальная моноамниотическая двойня. Состояние после лазерной коагуляции сосудов.

Из данных анамнеза - беременная соматически здорова, с неотягощенной наследственностью, нормального физического развития.

Гинекологический анамнез - была выявлена эктопия шейки матки, по поводу первичного бесплодия в течение 5 лет проводилось обследование и лечение в медицинском центре. По результатам обследования диагностирован мужской фактор бесплодия.

Данная беременность первая, в результате ЭКО.

При первом ультразвуковом исследовании в сроке 12 недель 3 дня диагностирована двойня. Неразвивающаяся беременность 2 плода на сроке 8 недель. Размеры первого плода соответствуют 12 неделям акушерского срока, грубых врожденных пороков развития не выявлено.

Второе ультразвуковое исследование было проведено в сроке 19-20 недель гестации, где описываются следующие пороки развития у ранее «погибшего плода»: плода акардиальный, масса плода составляет $54.9 \%$ от массы живого плода, отсутствуют тазовые кости и нижние конечности, голова и верхняя часть туловища, визуализируются зачатки органов брюшной полости. Амниотическая септа не визуализируется. Многоводие. Второй плод соответствует сроку гестации.

В динамике было произведено ультразвуковое исследование в сроке 20-21 неделя: масса акардиального плода составляет $50.40 \%$ от массы первого плода, в динамике многоводие с незначительным нарастанием. При проведении ультразвукового исследования в скрининговом режиме, отметило продолжающийся рост аномально развитого плода, масса которого составляла $72.48 \%$ от массы первого плода, многоводие со значительным нарастанием. Учитывая развитие синдрома обратной артериальной перфузии (синдром фетоаморфуса) у пациентки с монохориальной моноамниотической двойней в сроке 24 недели 3 дня в родильном доме г. Санкт-Петербург проведены: лазерная коагуляция магистральных сосудов (анастомозов) плода - acardius с предварительным проведением кариотипирования плодов, и трансабдоминальный амниоцентез, амниоредукция в объеме 2000 мл амниотической жидкости на фоне введения b-миметиков. По результатам цитогенетического исследования плода - кариотип клеток плаценты 46, XX, хромосомная патология исключена с вероятностью 99.8\%. В послеоперационном периоде пациентке наложен акушерский пессарий «Арабин».

В динамике в сроке 25 недель 6 дней проведено контрольное эхографическое исследование: наличие кровотока в магистральных сосудах плода-acardius не выявлено, околоплодные воды у плода-помпы в норме, показатели плодовоплацентарной гемодинамики не нарушены.

При повторном ультразвуковом исследовании в сроке 28-29 недель плодово-плацентарных нарушений не выявлено, плод соответствует сроку гестации, без патологии. В динамике при проведении УЗИ в сроке 31-32 недели в структуре плаценты выявлен кальциноз, соответствует второй степени зрелости, плод 
соответствует сроку гестации, многоводия не выявлено, плодовых и плацентарных нарушений нет, масса акардиального плода составляет 133 грамма.

В сроке 35-36 недель беременная поступает в стационар с диагнозом: Вызванная беременностью гипертензия. Проведено корректное обследование и лечение, с положительным эффектом. При ультразвуковом исследовании в условиях стационара, плод соответствует сроку гестации, без патологии, нарушений со стороны фетоплацентарного и плодово-плацентарного кровотока не выявлено, плацента соответствует третьей степени зрелости с кальцинатами. Акардиальный плод «мумифицирован», прижат справа к стенке матки. В связи с положительной динамикой от проводимой терапии гестационной гипертензии пациентка была выписана под наблюдением врачей женской консультации и с рекомендациями на дородовую госпитализацию.

Беременная в сроке 37-38 недель гестации поступает в стационар на дородовую госпитализацию и родоразрешение. По результатам обследования у женщины патологии не выявлено, плод соответствует 38-недельному сроку, без нарушений со стороны плодово-плацентарного кровотока. В плановом порядке была проведена операция кесарево сечение. Родоразрешилась живой доношенной девочкой, массой 2520 граммов, длиной 47 см, с оценкой по шкале Апгар 8/8 баллов, с признаками задержки внутриутробного развития 1 степени по гипотрофическому типу. По данным нейросонографии выявлен умеренный перивентрикулярный отек головного мозга, субэпендимальная киста справа размером 4.0*5.0 мм. Извлечен второй акардиальный плод массой 105 граммов, длиной 22 см с кожными покровами бледно-серого цвета и множественными пороками развития: структуры лицевого черепа в зачаточном состоянии, без наличия естественных отверстий, нижние конечности отсутствуют, верхние конечности деформированы, место прикрепления пуповины ближе к тазовому концу. При осмотре последа: пуповина «нормального плода» была длиной 50 см, имела две артерии и одну вену. Пуповина акардиального плода отходила от пуповины «нормального» плода на 5 см, и имела оболочечное прикрепление, сероватокоричневого цвета с кровоизлияниями. По данным патологистологического исследования: первая пуповина содержала три сосуда - две артерии и одну вену, вторая пуповина с аутолитическими изменениями, спавшимися сосудами. Экстраплацентарные оболочки - пролиферация клеток трофобластического слоя, кровоизлияния. Ворсины хориона представлены стволовыми, промежуточными дифференцированными и недифферинцированными с пролиферацией хориального синцития и полнокровием сосудов, другие ворсины (редуцированного плода) представлены стволовыми, промежуточными ворсинами, на уровне промежуточных ворсин отмечается наличие хаотично склерозированных ворсин с отсутствием в строме сосудов. Послеоперационный период женщины и период новорожденности протекал без осложнений, выписаны на 4 сутки.

\section{Выводы}

В данной статье был представлен типичный случай синдрома обратной артериальной перфузии. При подобных проявлениях данного синдрома пренатальная диагностика не представляет значительных сложностей. Важность своевременного пренатального выявления заключается в определении тактики ведения беременности в связи с прогностически неблагоприятным исходом для «нормального» плода. 


\title{
MULTIPLE PREGNANCY
}

\author{
Evgenia D. Garmaeva \\ Candidate of Medical Sciences \\ Head of State Budgetary Healthcare Institution "Minicipal Perinatal Centre \\ E-mail: elenabotoeva@list.ru
}

Elena A. Botoeva

Candidate of Medical Sciences, Associate Professor,

Dorzhi Banzarov Buryat State University

36a Oktyabrskaya st, Ulan-Ude, 670002, Russia

E-mail: elenabotoeva@list.ru

Currently, it has been identified the incidence of multiple pregnancies is increasing. This is due to the extensive use of oral contraception, after the abolition of which there is a spontaneous maturation of two or more follicles, as well as the introduction of additional reproductive technologies associated with the induction of superovulation. Monochorial pregnancy, among the entire number of multiple pregnancies, is the most prognostically unfavorable. Perinatal complications and mortality in such a pregnancy is $10 \%$, which exceeds the level of complications with dichorial twins by 3-4 times. The reasons for this situation lie in the structural features of the common placenta: often the existence of placental vascular anastomoses can lead to hemodynamic imbalance between twins. Syndrome of reverse arterial perfusion in twins is one of the most striking manifestations of abnormal vascular anastomosis in the monochorion placenta and is manifested by fetal malformations (the so-called malformations — "acardial monster", "anencephalic acardia").

The article discusses the problem of complications associated with multiple pregnancy, as well as describes the case of prenatal diagnosis of reverse arterial perfusion syndrome with monochoricmonoamniotic twins.

Keywords: multiple pregnancy, reproduction, superovulation, maturation 